\title{
C-Type Lectin Domain Family 12 Member A
}

National Cancer Institute

\section{Source}

National Cancer Institute. C-Type Lectin Domain Family 12 Member A. NCI Thesaurus. Code C162378.

C-type lectin domain family 12 member A (265 aa, $31 \mathrm{kDa}$ ) is encoded by the human CLEC12A gene. This protein is involved in carbohydrate binding and signal transduction. 